\title{
Impact of Public Health on Society
}

\author{
RUTH B. FREEMAN, R.N., Ed.D.
}

$\mathbf{P}$ UBLIC HEALTH action is at least as old as recorded history. Wherever men have lived together, they have set up regulations to govern their health practices. However, the modern public health movement-a broad-scale, concerted community action-is of more recent origin. It has grown out of the great social changes of the industrial revolution and out of the great political struggles that have brought more and more freedom and opportunity to the peoples of the world. Now public health is moving into a new era, an era of space, of discovery, of kaleidoscopic change. It is opportune to think again of our mission as public health workers and of the impact of our profession of public health on society today.

If you ask people what they think about this task in which we are engaged, their responses will vary all the way from "Public health does good," to "Really, the job of public health is over. We have licked communicable disease and our sanitation problems, and we need only a minimal maintenance service." Many of our professional statements are equally vague or limited in the concept of public health that they present to the public. Descriptions of programs tell what is to be done and what is done, but rarely is there any mention of why public health action is so essential. The objectives of public health are frequently not clear, and all too often

Dr. Freeman is associate professor of public health administration at the Johns Hopkins University. She delivered the address from which this article was taken before the Puerto Rico Public Health Association in San Juan, February 3, 1960, while she was a temporary staff member of the Rockefeller Foundation. they are stated in terms that are either vague or narrowly operational, "to provide maternal and child health supervision" or "to control tuberculosis," for example.

To the question, Why public health action? everyone comes up with a different answer. To me, the mission of public health is to bring to bear in a synthesized way all available scientific, educational; and social skills, knowledges, and discoveries so that they become operative promptly as agents for the betterment of individual, family, and community health. You will notice that this does not say the mission of the public health department or of public health workers, but rather of the total public health movement. The action to bring these forces to bear for social betterment may be taken by public health departments, voluntary agencies, private physicians, industry, or even individuals, their families, and their neighbors. Any or all of these may become part of general public health action. This is one of the unique aspects of our work, that it involves the community as a whole, just as it benefits the community as a whole.

The objective in public health is in some way to put to work for people what we have learned about the forces that motivate and activate groups, about tranquilizers, about the relation of oxygen therapy to retrolental fibroplasia, about the genetic factors that influence the drug resistance of certain organisms-all the diversified knowledge available. Some idea of the effect organized action may have on the lag between discovery and application is evident from a comparison of, for example, the time it took for the discoveries of Holmes and Semmelweiss to reduce the death rate of par- 
turient mothers with the time it took to get the Salk vaccine from the laboratory into the arms of children.

\section{What Is Public Health?}

Looking further at this job of ours, it may be profitable to distinguish among public health, public health practice, and public health services. Public health, stated simply, may be conceived of as a state of well-being of the community, including the physical, mental, and social aspects of health. Basic to public health is the health of the individuals that make up the public. Our present-day concept of wellness, as contrasted to the concept of absence of disease, as a goal sets a standard of health both different from and broader than that of the past. We are seeking optimal adaptation to disability or disease as well as freedom from preventable disease or illness, freedom from disabling ways of thinking or behaving as well as freedom from poor posture or inadequate nutrition. Under this definition, personal isolation, for example, or distorted values that prevent people from functioning as happy individuals and social beings would become part of the health picture.

However, community health is more than the sum total of all individual health. In our country, the family is a focal social unit, and the health of the family is considered essential for our national well-being. If family members lack mutual support or are so tightly tied to one another that they are smothered by mutual overdependence, we may have healthy persons in a family which is not healthy. Community health is even broader in its implications than family health. In addition to healthy individuals and healthy families, the healthy community must also have the facilities, the group character, the kinds of interrelationships within the community as a whole that make it possible to maintain health. For example, healthy people living next to a polluted stream are living in an unhealthy community because there is a constant threat to health.

People in a community who have not learned to work together as neighbors will have trouble handling their community health problems effectively. The self-help housing program here in Puerto Rico, for example, is contributing to health not only by creating a better environment, but also by fostering neighborly interdependence and developing in the people an ability to work constructively together that should carry over to such problems as helping a neighbor recognize the need for medical care, or providing friendly supporting services needed by the long-term patient, or understanding the need for tax support for health services to reach all the people.

What we want, then, is a community in which responsible, knowledgeable individuals protect and conserve their own and their family's health and contribute to the maintenance of the health of their neighbors and of their community through action, through tax support, and through their own personal support and understanding.

When we look at this goal, it becomes apparent that public health practice must be more than the carrying out of a few preventive medical procedures. The job requires the application of multiple professional skills for community diagnosis and the application of medical, educational, social, or environmental therapy for maintaining health, for mobilizing the public, for assuring the necessary health action.

If this premise is accepted, it becomes obvious that public health cannot be the province of any one profession. Public health is not simply medical care in which different skills are needed, nor is it health education alone. Community diagnosis, one of the fundamental skills of public health, entails knowledge of the existence of disease and of the level of susceptibility to certain types of health problems. Susceptibility to tuberculosis, for instance, may be shown by the epidemiological characteristics of the disease; or to diphtheria, by the immunization status; or to juvenile delinquency, by predelinquent behavior or social disorganization. Community diagnosis requires, too, knowledge of the competence of the population in relation to its own health care, as well as the adequacy and extent of private medical care, the number and distribution of hospitals and diagnostic facilities, and how frequently they are used and by whom. The methods by which people communicate with one another, the ways in 
which they take action on community problems, and the economic and social competence of the community are also essential components of the community's health. Only when the community is seen "in the round" in this way is it possible to plan effectively for the public health program the people need.

Public health services have been described in so many different ways that it would be impossible to present fairly all the points of view. To me, public health service is whatever health service the public decides can best be provided through organized rather than individual effort. Public health service is not limited to preventive care, since preventive care is an integral part of all medical practice, wherever it may be and under whatever auspices. There is no list of five or six or seven areas that are the only appropriate public health activities, and the size of a problem cannot be considered a legitimate criterion of its appropriateness for public health action.

While it is the public's responsibility to decide what it prefers to provide as a group, it is the responsibility of the public health profession to provide information pertaining to needs and ways of meeting them so that the public is able to make a wise decision. It is also the responsibility of the profession to control professional practice, for this is not a matter in which the public is competent. For example, it is a public responsibility to decide whether vaccination will be provided through community clinics supported from tax funds or primarily by individual medical practitioners. It is the responsibility of the professional group to see to it that the vaccination procedures are safe and properly tested, that those who administer the vaccine are qualified, and that the public is informed of the probable outcomes of the program that is undertaken.

\section{Its Effects on Society}

If we conceive of public health practice and services in this broad context, it is obvious that they will have a profound impact on the general welfare. If a man is cured of active tuberculosis so that he can maintain himself and his family, and if the family is kept intact while at the same time the community is protected from infection, the hazard of related illness or emotional stress is reduced, as is the likelihood of continuing indigence. This result represents a good investment. If we think of the plus factors that may be gained through highquality public health services in tuberculosis, we may find that the family is strengthened, that teaching regarding general hygiene protects the family not only in relation to tuberculosis but in other ways as well, that through their experience with this disease they get a better understanding of how to use hospital and diagnostic facilities for other types of health care. The tuberculosis program addressed to the general public may not only inform people about tuberculosis and motivate them to obtain early diagnosis but may, in addition, teach them about the overall public health program and their part in promoting it.

Public health services may also have a definite impact on the values of people served. To the degree that a public health worker considers the patient as a person and shows a willingness to listen to and learn from him, and to the degree that the public health worker expects the patient to contribute to his own, his family's, and his community's help, public health services can serve to develop values that are consistent with our democratic way of life.

Public health may also have a decided impact on the education of the professional group that constitutes the public health team. Public health action requires the synthesis of efforts of many individuals and groups. This raises the question of how we can best teach professional workers to function in this integrated way. What requirements does this set up for orientation of professional workers to the activities of those in different fields of work? For joint learning? For relating and phasing of professional education in the several fields so that we have the personnel we need when we need them? For example, as the character of medical practice changes, new kinds of obligations may be placed on nurses, on physical therapists, on medical social workers, and on health educators. Unless basic and continuing education in these four related fields is adapted to developments in medicine, the products of professional schools in those fields will not be ready to work effectively with one another. 
Public health services may also have a distinct impact on community social structure. Public health programs designed so neighbors can help neighbors produce social patterns that may carry over to other things. As people group together to build a house or dig a well or to take a class in baby care or first aid, they learn a way of doing things that may remain with them when the problem is one of civil defense or epidemic or a way that will make it easy to work together for a diagnostic clinic or a mass vaccination program.

The influence we exert as public health workers may be individual as well as professional. The way in which we do things ourselves, as well as what we do, may have an effect on those we serve.

The ways in which we act in concert with members of other professions through our pub- lic health associations and through our individual disciplines and their associations also have importance in strengthening the impact of public health services on society. Membership in an association may mean simply attending annual meetings and social events. Or it may mean becoming involved with the concerted thinking, decisions, and actions that are needed if the organization is to function as an important social force. Through the channels of our organizations we can do much not only to bring to the public the best possible health care but also to enlarge our own understanding and to use our personal as well as our professional skills to contribute more and more to the general welfare. In this way we extend our horizons and deepen our perceptions so that in the future our profession of public health can truly fulfill its bright promise.

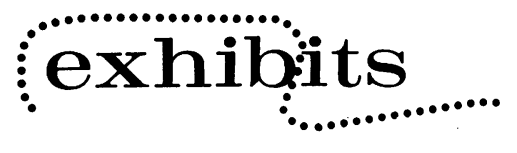

\section{Federal and State Radiological Health Goals}

As part of its program of technical assistance to the States, the Division of Radiological Health, Public Health Service, designed this exhibit to show how Federal-State relationships can be strengthened and to stimulate continued growth of comprehensive radiological health programs.

The exhibit delineates the major objectives of Federal-State programs with respect to public exposure to ionizing radiations from all sources. It shows how these goals can be achieved through a concerted program of measurement, assessment, control, and reduction of public exposure. It lists the elements of a comprehensive radiological health program as recommended by the

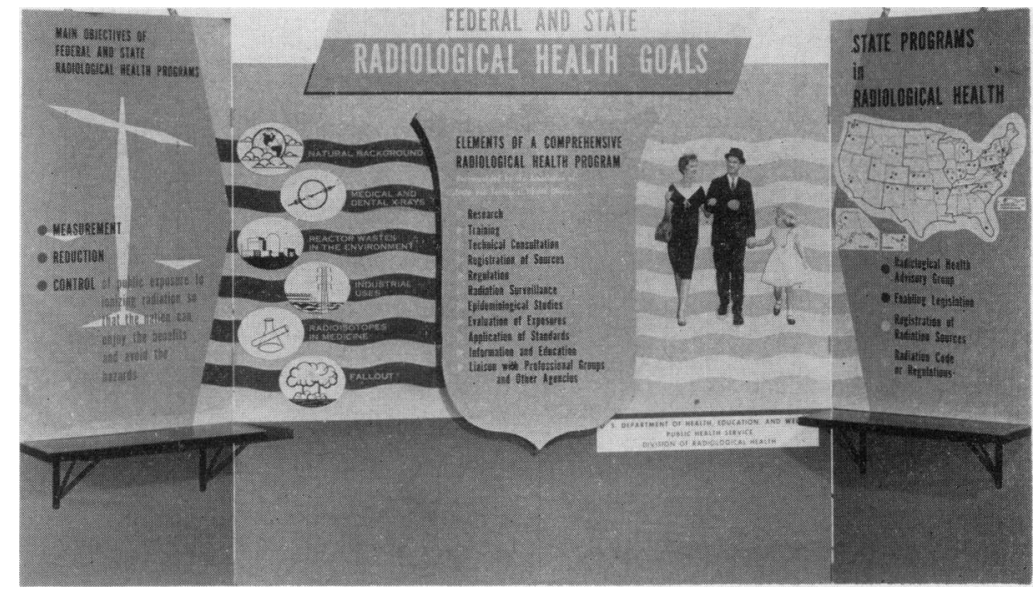

Specifications: A free-standing, 3-panel exhibit, 10 feet long, 7 feet high, and 2 feet deep; total weight approximately 380 pounds including a single packing crafe. Lighting fixtures require one 600-watt outlet. Shelves are provided on each side panel for displaying literature.

Association of State and Territorial Health Officers.

The exhibit also points out graphically States which have a radiological health advisory group, those with enabling legislation, those requiring registration of radiation sources, and those which have radiation codes or regulations.
It is available for loan without charge, exclusive of shipping costs.

Further information, including arrangements for borrowing, can be obtained from the Division of Radiological Health, Public Health Service, U.S. Department of Health, Education, and Welfare, Washington 25, D.C. 